\title{
LA RELEVANCIA DE LA FILOSOFÍA EN LA OBRA DE J.L. BORGES
}

\author{
Rubén Benítez Florido \\ Universidad de La Laguna \\ benitezruben@gmail.com
}

\section{RESUMEN}

Este artículo analiza el significado y el alcance que tiene la filosofía en la obra de J.L. Borges. No es solo que los contenidos filosóficos hayan contribuido a hacer aún más interesantes las ficciones de Borges; es que las narraciones de Borges han renovado el interés del público no especializado por teorías filosóficas tanto clásicas como actuales. Avanzaremos primero desde un planteamiento biográfico, en el que indagaremos en la importancia de la educación filosófica en la formación del joven Borges, para luego profundizar en esta simbiosis entre literatura y filosofía que constituye una de las características esenciales de su obra.

PALABRAS ClAVE: singularidad, literatura, racionalidad, verdad, postmodernidad.

\section{THE RELEVANCE OF PHILOSOPHY IN THE WORK OF J.L. BORGES}

\section{Abstract}

This article analyzes the meaning and scope of philosophy in the work of J.L. Borges. It is not only that the philosophical content has contributed to make Borges' fictions even more interesting; Borges' narratives have also renewed the interest of the non-specialized public for both classical and current philosophical theories. Starting from a biographical approach, the importance of the philosophical education in the formation of the young Borges will be evaluated. The symbiosis between literature and philosophy that constitutes one of the essential characteristics of Borges' work will also be explored.

KEYWORDS: singularity, literature, racionality, truth, postmodernity.

DOI: http://doi.org/10.25145/j.laguna.2018.43.003 


\section{INTRODUCCIÓN: UN ARGENTINO EXTRAVIADO EN LA METAFÍSICA}

No hay ejercicio intelectual que no sea finalmente inútil. Una doctrina filosófica es al principio una descripción verosímil del universo; giran los años y es un mero capítulo -cuando no un párrafo o un nombre- de la historia de la filosofía.

Jorge Luis Borges, Ficciones

En el «Prólogo» a Nueva refutación del tiempo, Borges escribió que prefería considerar el conjunto de su obra -que abarca géneros tan dispares como poesía, narrativa y ensayo-, no tanto como el corpus riguroso de un escritor metódico, sino como el "débil artificio de un argentino extraviado en la metafísica»"

Muchos años más tarde de haberla incluido en uno de sus libros de ensayos, casi como por descuido, esta autopresentación será confirmada en repetidas ocasiones por un Borges ya anciano y un tanto abrumado por la fama durante el transcurso de numerosos encuentros con periodistas literarios y seguidores de su obra, en los que Borges rememora con cierta nostalgia cómo su padre le contagió su interés por la filosofía cuando todavía era un niño ${ }^{2}$.

Por los datos contenidos en sus biografías, resulta bastante fácil imaginar a un Borges aprendiz de filósofo, escritor en ciernes y «tejedor de las naderías del arte», dejándose seducir por los laberintos abstractos de las paradojas de Zenón, que su padre desplegaba ante él con el mismo rigor que un filósofo de la escuela de Elea, la consumada habilidad de un sofista y la sutileza de un prestidigitador ${ }^{3}$.

Sin llegar a imaginar, ni siquiera a intuir, en aquel momento la importancia decisiva que aquellas tardes de discusiones filosóficas en compañía de su padre tendrían en el conjunto de su obra, como después veremos, la mente del joven Borges se empapó como una esponja con algunas de las lecciones más básicas de la Historia de la Filosofía, de la mano de los padres griegos que inauguraron la disciplina, allá por los siglos v-VI a.C.

Esta intensa convivencia con la filosofía desde una edad muy temprana (y que se prolongará hasta el final de su vida), indisociablemente unida a su predilección por la ficción narrativa, será el germen de algunas de sus afirmaciones más provocativas (y aparentemente contradictorias), desde el punto de vista de la tradición filosófica occidental, acerca de la naturaleza literaria de cualquier texto filosófico.

A lo largo de este artículo, tendremos ocasión de analizar el significado y alcance que tienen estas (¿polémicas?) afirmaciones dentro del universo borgiano, así como las múltiples resonancias que dichas afirmaciones han tenido en el ámbito de la literatura y de la filosofía.

${ }^{1}$ Borges, J.L. Obras completas, I, RBA, Barcelona, 2005, p. 757.

2 Por ejemplo, cf. Borges, J.L. y Ferrari, O. Diálogos, Seix Barral, Barcelona, 1992, p. 229.

3 Cf. Fernández Ordóñez, S. La mirada de Borges, Alfama, Málaga, 2008, pp. 24-26,

$38-41$. 


\section{PLANTEAMIENTO DEL PROBLEMA: "LENGUAJE DE LA FICCIÓN" VERSUS "LENGUAJE DE LA VERDAD"}

Los filósofos más apegados a los cánones delimitados por la tradición no tienen ninguna duda de la línea que separa la literatura y la filosofía, el «lenguaje de la ficción» y el «lenguaje de la verdad». Según estos autores, la tarea de la filosofía consiste en elucidar el «lenguaje de la verdad», entendiendo por este la representación fiel de la realidad.

A diferencia del «lenguaje de la ficción», el «lenguaje de la verdad» se caracterizaría por desterrar de su seno cualquier atisbo de ambigüedad, de subjetividad o de parcialidad, en parte gracias a los asépticos procedimientos que proporciona la argumentación lógica (garantes de la objetividad y de la imparcialidad), y, en palabras de Richard Rorty, autoproclamarse como un «espejo fiel de la realidad» que trata de representar ${ }^{4}$. Por su parte, el «lenguaje de la ficción», que es el que utiliza la literatura, perseguiría la belleza estética a partir de ciertas reacciones emocionales provocadas en el lector 5 .

Además de los contrastes evidentes sobre los objetivos y las características entre estos dos tipos de lenguaje, otra diferencia importante podemos encontrarla en algunos de sus procedimientos expresivos.

Así, en las obras de ficción literaria es frecuente el recurso de la elipsis, esto es, la destreza en omitir cierta información cuyo contenido puede fácilmente sobreentenderse. En cambio, el rigor de la demostración filosófica no permite ningún salto u omisión en los pasos de la argumentación, pues esto implicaría perder un eslabón en la cadena del razonamiento que debería conducirnos hasta una conclusión (recordemos que, según las estrictas reglas de la lógica, la conclusión debe extraerse necesariamente de la correcta concatenación de unos pasos a seguir desde unas premisas, con la ayuda de unas reglas formales).

A diferencia del escritor que hilvana una historia de ficción, poco o nada tiene que ver la capacidad creativa del filósofo en este procedimiento, excepto en la elección de las reglas a utilizar para llegar hasta la conclusión final. Pero, incluso, en este último caso, nos inclinamos a pensar que el resultado final depende más de su destreza racional para resolver un problema formal que de su imaginación.

${ }^{4}$ Cf. Ronty, R. La filosofía y el espejo de la naturaleza, Cátedra, Madrid, 1995, p. 337 y ss.

${ }^{5}$ A pesar de que estas sean, en efecto, las directrices predominantes tanto en el ámbito de la filosofía como en el de la literatura, un simple vistazo a los autores de ambas disciplinas bastaría para evidenciar que no faltan las excepciones ilustres a tan rígido programa. Por por citar solo dos casos de los más emblemáticos, nadie dudaría en calificar a Platón y a Nietzsche como eminentes filósofos y, sin embargo, también utilizan en sus libros la literatura como vehículo de sus teorías, como lo demuestran los Diálogos y Asi habló Zaratustra, obras a medio camino entre la literatura y la filosofía. Abundan, además, los ejemplos de otros autores (como Voltaire, Camus, Sartre, Unamuno o Benjamin) que han cultivado ambos géneros con éxito y a los que resulta muy difícil encorsetar dentro de esta clasificación; o incluso novelistas cuya obra ha sido calificada como de alto interés filosófico, como es el caso de Kafka o, más recientemente, el de Milan Kundera. 
Aunque no sea más que un mero ejemplo, esta diferencia sobre los procedimientos literarios y los filosóficos nos sirve para ilustrar por qué el «lenguaje de la ficción» no es el instrumento tradicionalmente más adecuado para la tarea de representar fielmente la realidad y, por principio metodológico, queda excluido del quehacer filosófico.

En contra de esta manera de pensar, perteneciente a la vieja escuela, Borges llegará a decir en Otras inquisiciones (1952), uno de sus libros de ensayos más conocidos, que "las invenciones de la filosofía no son menos fantásticas que las del arte» («Magias parciales del Quijote») ${ }^{6}$; o que estima «las ideas religiosas o filosóficas por su valor estético y aún por lo que encierran de singular y maravilloso» ("Epílogo») pero no por su pretensión de universalidad.

De esta forma, renunciando explícitamente al más antiguo y firme de los objetivos de la metafísica tal y como fue inaugurada por Aristóteles (la búsqueda incesante de la verdad, promovida por el afán natural de conocimiento del ser humano), haciendo gala de un escepticismo radical y acercándose a las conclusiones más recientes de la filosofía postmoderna sin ser consciente de ello ${ }^{8}$, Borges afirma en "Avatares de la tortuga», otro breve ensayo perteneciente al libro Discusión (1932), lo siguiente:

Es aventurado pensar que una combinación de palabras (otra cosa no son las filosofías) pueda parecerse mucho al universo. También es aventurado pensar que de esas coordinaciones ilustres, alguna -siquiera de modo infinitesimal- no se parezca un poco más a las otras?.

Con todo lo anterior, que ya es mucho, hay que tener en cuenta no solo la radicalidad de su propuesta en el ámbito de la filosofía (pues vendría a contradecir, en buena medida, los presupuestos básicos de la tradición filosófica occidental), sino también la renovación dentro del panorama de la literatura, al utilizar ciertos temas y procedimientos que tradicionalmente habían sido excluidos de la narrativa de ficción.

Y es que, igual que hemos visto en el ámbito de la filosofía, Borges también se rebela contra los cánones habituales de la literatura, adelantando caminos que recorrerán las generaciones siguientes de escritores, en coherencia con su concepción de la filosofía (como una "ramificación de la literatura fantástica») y de la literatura (en la que todo vale, como utilizar temas reservados al ámbito de la filosofía, con tal de sorprender al lector).

${ }^{6}$ Borges, J.L. Op. cit., p. 669.

7 Ibidem, p. 775.

8 «Otra razón del inmenso prestigio internacional de Borges era que sus cuentos se percibían como anticipaciones de algunos de los temas principales de la teoría crítica moderna [...]. En este sentido, Borges parecía haber prefigurado muchos de los temas de la condición "postmoderna"”, Williamson, E. Borges, una vida, Seix Barral, Barcelona, 2007, p. 11.

9 Borges, J.L. Op. cit., 258. 
Lo que hace Borges es utilizar como argumentos de ficción en sus relatos y en sus poesías aquellas teorías filosóficas que su padre le enseñaba en la biblioteca de su casa, y que él, posteriormente, seguirá hilvanando a lo largo de sus creaciones literarias con una precisión de relojero.

No hay más que comprobar la sorprendente elección de un título como Historia universal de la infamia (1935), con evidentes resonancias metafísicas, a simple vista más idónea para un tratado filosófico que para un libro de relatos, en su primera incursión dentro de la literatura de ficción.

También lo son las extensas digresiones de carácter reflexivo que intercala en sus relatos, o al menos en algunos de los más conocidos (como veremos que ocurre en «El inmortal»), y que le han granjeado, en no pocas ocasiones, la etiqueta peyorativa de «escritor frío y descarnado", «escritor para élites» o, incluso, de «escritor para escritores».

Sin embargo, lejos de representar un obstáculo para disfrutar de su obra, o un problema añadido para determinar la naturaleza de sus creaciones, pensamos que estas singularidades no solo no le restan, sino que le añaden interés al conjunto de su obra.

A juzgar por las numerosas declaraciones que concede en sus entrevistas tardías, pensamos que Borges cada vez se fue sintiendo más cómodo cultivando esta alianza fructífera entre narrativa, poesía y ensayo, como demuestra el formato misceláneo de su libro El hacedor (1960), que Borges publica cuando ya era un escritor de fama reconocida, y que recoge un poco de cada uno de estos géneros.

Podría decirse, incluso, que con la llegada del reconocimiento y de la fama, Borges cada vez se preocupa menos de realizar clasificaciones internas de su obra, y prefiere señalar que él es un autor obsesionado con unos pocos temas que no ha hecho más que cincelar de diferentes maneras (a través de diferentes géneros) a lo largo de su vida ${ }^{10}$.

Cabría preguntarse cuál es la relación mutua entre la literatura y la filosofía, en el conjunto de la obra de Borges. Y aunque no exista una respuesta unánime ni definitiva a este interrogante entre los intérpretes de su obra, podemos aventurar algunos indicios que ayuden a clarificarla, como veremos en el penúltimo apartado, a propósito de un análisis del relato «El inmortal», y su estrecha relación con ensayos como «Historia de la eternidad», «La doctrina de los ciclos», «Nueva refutación del tiempo»o «El tiempo circular».

Pero, antes de eso, quizás habría que analizar cuál ha sido la recepción de la obra borgesiana tanto en el ámbito de la filosofía como en de la literatura.

${ }^{10}$ Cf. Borges, J.L. y Ferrari, O. Op. cit., p. 19. 


\section{RECEPCIÓN CRÍTICA DE LA OBRA DE BORGES}

Borges no es considerado un filósofo por la crítica especializada ni por sus lectores ni mucho menos por él mismo; no frecuenta los círculos académicos de pensamiento; no pertenece a ninguna corriente filosófica concreta ni proporciona un corpus teórico original (a la manera de los grandes pensadores) por el que sea recordado.

Se puede afirmar todo esto sin riesgo a equivocarnos, a pesar de que Borges cultivara el ensayo mucho antes que el relato corto (género por el que es mundialmente famoso) y de que en algunas ocasiones encontremos argumentos de gran calado filosófico en sus ficciones literarias, como tendremos ocasión de mostrar en el siguiente apartado.

La erudición que rezuman sus ensayos, el diálogo que establece con las teorías más importantes de pensadores clásicos y modernos, es el fruto de una intensa pasión autodidacta, tal y como hemos visto, alimentada desde la niñez por sus lecturas al abrigo del cálido y sosegado ambiente familiar.

En sus ensayos, Borges simplemente se hace eco de algunos de los problemas filosóficos más importantes de la tradición occidental y consigue adelantar algunas posturas teóricas que desarrollarán corrientes de pensamiento posteriores, como el postmodernismo.

En cuanto a su faceta como poeta y como narrador, es comúnmente aceptado que Borges utiliza ese bagaje filosófico como fuente de inspiración para articular su literatura, cuyos temas y argumentos se ven enriquecidos con motivos que tradicionalmente habían sido excluidos del ámbito literario.

Así, en sus libros de poesía no es extraño encontrar glosas dedicadas a Heráclito o a Descartes. Y en sus relatos de ficción encontramos temas filosóficos de difícil inclusión dentro de este género, como la hipótesis de la eternidad en la subjetividad, la muerte como experiencia singularizadora, el papel del olvido y la memoria en la construcción del conocimiento, el espacio y el tiempo como delimitadores de la identidad o la construcción lingüística de la realidad.

Debido a estos motivos, podemos concluir que una de las originalidades de los relatos de Borges reside precisamente en el novedoso tratamiento literario de problemas filosóficos conocidos (el «lenguaje de la ficción» entremezclado con el «lenguaje de la verdad»), o, dicho con otras palabras, en la creación de tramas narrativas al servicio de argumentos racionales.

Esta es la opinión de S. Fernández Ordóñez cuando afirma lo siguiente: «El esteticismo de Borges, ya indiscutible, no es ornamento frívolo o columna menor en su obra sino la vía para expresar su concepción de la existencia. En él, idea y forma, filosofía y estética están fusionadas y unas viven a través de las otras, convirtiendo en baladí cualquier intento por decidir si importa más en su obra el pensar metafísico o la forma literaria ${ }^{11}$. Sin embargo, a partir de aquí, resulta

11 Fernández Ordónez, S. Op. cit., p. 43. 
necesario matizar las diferentes posturas sobre esta simbiosis entre literatura y filosofía en la obra de Borges.

Quizás la más extendida sea la postura que enfatiza la extraordinaria originalidad del tratamiento literario sobre la importancia de los temas filosóficos, puesto que estos últimos ya pertenecían al acervo de la tradición filosófica occidental antes de que Borges los convirtiera en motivo de sus creaciones. Como señala J. Nuño, en un famoso estudio sobre el papel de la filosofía en la obra de Borges:

Es innegable que Borges encierra temas de valor metafísico, pero justamente eso: el encierro vale más que los temas. Y el temor del comentarista es siempre el de maltratar o echar a perder o preterir la maravillosa envoltura [...]. Pero lo mejor es que para lograr la expresión de esas abstractas nociones, Borges levanta la imaginería de sus poderosos símbolos literarios. Dicho así, con términos del trillado vocabulario filosófico, no pasaría de ser un inane corolario de media docena de viejas ideas metafísicas. Lo bueno es que jamás Borges lo dice así: lo dice en y a través de sus relatos y ensayos, con el suficiente vigor literario como para cobrar vida propia y poder existir, en tanto obras de creación artística, sin ninguna necesidad del apoyo interpretativo metafísico ${ }^{12}$.

Una segunda postura, sin llegar contradecir del todo la postura anterior, prefiere hablar de una fértil alianza entre literatura y filosofía, de la que ambas disciplinas resultan ampliamente beneficiadas y enriquecidas.

Aceptado el diagnóstico de que la literatura ha ampliado su ámbito gracias a la inclusión de nuevos temas, esta última postura sostiene que la filosofía también ha conseguido ampliar su ámbito particular, en parte gracias a la propia popularidad de la obra de Borges.

Como representante de esta postura, podríamos citar a Fernando Savater, gran admirador de la obre de Borges, que señala lo siguiente: «Sin duda a Borges le vino bien la filosofía como inspiración, pero no es menos cierto que Borges también les ha venido bien a los filósofos, sea como inspiración directa, como apoyo o como razonable ornamento. Esta interacción merece ser resaltada $»^{13}$.

Ejemplos de esta interacción señalada por Savater son las numerosas referencias a Borges que podemos encontrar en las obras de filósofos; tal es el caso de Michel Foucault, que comienza uno de sus libros más conocidos con una mención explícita a un texto de Borges ${ }^{14}$.

12 Nuño, J. La filosofía en Borges, Reverso, Barcelona, 2005, p. 184 y ss.

13 Savater, F. "Borges y la filosofía», en De Toro, A. y Regazzoni, S. (eds.), El siglo de Borges, vol. II: Literatura-Ciencia-Filosofía, Editorial Iberoamericana, Madrid, 1999, p. 124.

14 «Este libro nació de un texto de Borges. De la risa que sacude, al leerlo, todo lo familiar al pensamiento -al nuestro: al que tiene nuestra edad y nuestra geografía-, trastornando todas las superficies ordenadas y todos los planos que ajustan la abundancia de seres, provocando una larga vacilación e inquietud en nuestra práctica milenaria de lo Mismo y de lo Otro», Foucault, M. Las palabras y las cosas, Siglo XXI, Madrid, 1978, p. 1. 
Casos como el de Foucault ponen de manifiesto cómo la obra de Borges representa también un laboratorio de ideas y una fuente de inspiración para los filósofos, y eso a pesar de (o precisamente por) la crítica que hace a la filosofía como representación privilegiada de la realidad, una característica que se encuentra en la base de su escepticismo.

\section{LA MUERTE COMO EXPERIENCIA SINGULARIZADORA: UN ANÁLISIS DE «EL INMORTAL»}

Un ejemplo paradigmático de la fructífera alianza entre literatura y filosofía que existe en la obra de Borges podemos encontrarlo en su relato "El inmortal» ( $E l$ Aleph).

El tema central del relato es el efecto que una hipotética inmortalidad provocaría en la existencia de los seres humanos. Su protagonista, un soldado romano, después de conseguir la tan ansiada inmortalidad, realiza la siguiente reflexión:

La muerte (o su alusión) hace preciosos y patéticos a los hombres. Éstos conmueven por su condición de fantasmas; cada acto que ejecutan puede ser último; no hay rostro que no esté por desdibujarse como el rostro de un sueńo. Todo entre los mortales, tiene el valor de lo irrecuperable y de lo azaroso ${ }^{15}$.

Si la analizamos con detenimiento, podemos comprobar que esta reflexión sobre el significado de la muerte para el ser humano coincide en sus líneas fundamentales con la realizada por Martin Heidegger en Ser y tiempo veinte ańos antes, y de la que es deudora una buena parte de la corriente existencialista.

El concepto de «ser-para-la-muerte» de Heidegger pone el énfasis en la muerte como hecho indisociable de nuestro ser (de ahí que el concepto se escriba de esa manera tan característica de la obra heideggeriana, enlazando las palabras que forman el concepto con guiones y sin separaciones entre ellas), con el objetivo de señalar su importancia en la vida del ser humano ${ }^{16}$.

Heidegger opina que al asumir la muerte como la extinción de toda posibilidad (la muerte es la posibilidad más «real»: aquella que anula al resto de posibilidades de la existencia humana), al ser humano no le queda más remedio que afrontar las decisiones que conforman su vida desde sí mismo, y no desde otros agentes externos a su propia existencia ${ }^{17}$.

15 Borges, J.L. Op. cit., p. 541.

16 Cf. Heidegger, M. Ser y tiempo, Trotta, Madrid, 2009, p. 269 y ss.

17 «La muerte es la posibilidad más propia del Dasein. El estar vuelto hacia esta posibilidad le abre al Dasein su más propio poder-ser, en el que su ser está puesto radicalmente en juego. Allí puede manifestársele al Dasein que en esta eminente posibilidad de sí mismo queda arrebatado al uno, es decir, que, adelantándose, puede escaparse siempre de él», ibidem, p. 279. 
La aceptación de la muerte como una «posibilidad real» es, por tanto, el primer paso para concebir la vida como un acontecimiento único e irrepetible, porque cada acto ejecutado en ella, tal y como señala Borges en el párrafo anterior, podría ser el último.

Según Borges, si fuésemos inmortales tendríamos una concepción de la vida menos dramática, pero también mucho más aburrida. Borges encuentra el germen de esta insólita afirmación, eje vertebrador de "El inmortal», en el análisis de las consecuencias de la "teoría del eterno retorno» en la obra de Nietzsche, aspecto al que dedica varios ensayos escritos algunos ańos antes ${ }^{18}$.

La interpretación ontológica de esta teoría (la única que contempla Borges en estos ensayos) ${ }^{19}$ afirma que el número de combinaciones posibles en un universo finito es también finito, aunque ciertamente desmesurado. Por eso, en un tiempo infinito, el número de combinaciones posibles debe por fuerza ser alcanzado en algún momento, aunque este sea muy lejano, y todo lo acontecido en ese universo finito volvería a repetirse.

Desde esta interpretación estrictamente ontológica, ¿qué implicaciones tiene el eterno retorno en la vida de los mortales? Poco, por no decir casi nada. La efímera vida de un ser humano es tan insignificante en medio de una hipotética repetición del tiempo cósmico que a nadie le está reservado el privilegio (¿privilegio?) de contemplar cómo todo se repite infinitamente.

Pero la respuesta cambia radicalmente si nos preguntamos por las consecuencias que tendría la repetición del tiempo cósmico en la vida de un ser inmortal. Esta es, precisamente, la pregunta filosófica que Borges trata de responder en su relato a través de una ficción literaria.

En un momento de «El inmortal», el protagonista encuentra a unos trogloditas innominados, de comportamientos extraños y de hábitos no menos estrafalarios, que habitan una ciudad de arquitectura imposible, y empieza a compartir su vida con ellos.

A lo largo de la narración, ese protagonista consigue trabar relación (si es que puede denominarse de esta manera) con uno de esos estrafalarios trogloditas, que no deja de seguirlo a todas partes. Al final de la tercera parte del relato, cuando casualmente el protagonista le pregunta al troglodita si sabe algo de la Odisea, este le proporciona la clave de su identidad al responderle que ya casi no se acuerda de nada, pues ya ¡han pasado mil cien años desde que la escribió!

${ }^{18}$ Cf. «La doctrina de los ciclos» $\mathrm{y}$ «El tiempo circular», ambos en Historia de la eternidad (1936).

19 Para una revisión sobre los diferentes niveles de interpretación en el discurso del eterno retorno, cf. Ávila Crespo, R. Nietzsche y la redención del azar, Universidad de Granada, Granada, 1986, pp. 319-346. Para afianzar la interpretación ética que considera la "teoría del eterno retorno" como una nueva formulación del imperativo categórico kantiano, complementaria al texto de Remedios Ávila, cf. Salgado, E. Cumbre y abismo en la filosofía de Nietzsche. El cultivo de sí mismo, Madrid, Plaza y Valdés, 2007, pp. 187-189. 
Es al comienzo de la cuarta parte del relato cuando se develan todos los misterios que su autor ha ido sembrando en él hasta ese momento: el protagonista inicial había conseguido beber el agua de la inmortalidad que tanto ansiaba; el extrańo lugar que ha descubierto es la caótica Ciudad de los Inmortales; los trogloditas que habitan la Ciudad y que manifiestan un comportamiento tan extravagante son todos inmortales, como él mismo; y el enigmático troglodita que no ha dejado de seguirlo a todas partes no es otro que el propio Homero, autor de la Odisea.

El descubrimiento azaroso de la identidad de Homero por parte del lector muestra que en la vida de los inmortales los acontecimientos de la existencia solo pueden darse como mera repetición.

Recordemos lo dicho anteriormente sobre la interpretación ontológica de la "teoría del eterno retorno»: el número de combinaciones posibles de un universo cerrado en un tiempo infinito es limitado y, por lo tanto, todo cuanto acontece está condenado a la repetición.

Según el relato de Borges, esta revelación muestra que desde la perspectiva de un inmortal cualquier logro (como escribir la Odisea) es insignificante, pues a lo largo de su vida infinita los inmortales van a poder realizar todas las posibilidades concebibles. Para Borges, esta revelación constituye un panorama desolador, mucho más desasosegante que el de saberse mortal, como explica en el relato:

Entre los Inmortales, en cambio, cada acto (y cada pensamiento) es el eco de otros que en el pasado lo antecedieron, sin principio visible, o el fiel presagio de otros que en el futuro lo repetirán hasta el vértigo. No hay cosa que no esté como perdida entre infatigables espejos. Nada puede ocurrir una sola vez, nada es preciosamente precario. Lo elegíaco, lo grave, lo ceremonial, no rigen para los Inmortales ${ }^{20}$.

Los actos de los inmortales son copias de todos aquellos que los antecedieron y, al mismo tiempo, un mero reflejo de todos los que los sucederán. La vida pierde aquello que la hace tan valiosa para convertirse en una mera repetición sin sentido: «Yo he sido Homero; en breve seré Nadie, como Ulises; en breve seré todos: estaré muerto $»^{21}$.

Lo que Borges trata de explicar es que la vida de los inmortales pierde el dramatismo y la fragilidad de los mortales, pero también pierde su carácter único e irrepetible: es una vida que carece de sentido, pues ha sido desprovista de todo aquello que la hace diferente de las demás: su singularidad, su fugacidad y su fragilidad.

No es de extrañar que al final del relato, después de haber conseguido la tan ansiada inmortalidad, su protagonista desee recuperar a toda costa su naturaleza mortal. En palabras de Heidegger, podríamos decir que el protagonista del relato por fin acepta su «ser-para-la-muerte», o lo que es lo mismo, vuelve a asumir la muerte como una experiencia singularizadora.

${ }^{20}$ Borges, J.L. Op. cit., p. 542.

${ }^{21}$ Ibidem, p. 543. 
Sin la muerte, los seres humanos no serían lo que son. Por eso, concluye Borges: «Ser inmortal es baladí; menos el hombre, todas las criaturas lo son, pues ignoran la muerte; lo divino, lo terrible, lo incomprensible es saberse inmortal ${ }^{22}$.

En este final de «El inmortal» se puede apreciar cómo a Borges le gusta trenzar sus ficciones literarias con argumentos filosóficos, que contienen la misma profundidad que los que podemos encontrar en la obra de Nietzsche o en la de Heidegger.

\section{A MODO DE CONCLUSIÓN}

Borges ha pasado a la Historia de la Literatura como el creador de un peculiar universo poblado de libros, tigres, laberintos interminables, ríos que simbolizan el devenir, espejos que representan el horror de la repetición, dobles de sí mismo, tableros de ajedrez como metáforas de la existencia, sońadores que son a su vez soñados por otros y bibliotecas infinitas que se convierten en paraísos insospechados para lectores impenitentes, como el propio Borges.

Estas imágenes recurrentes le permiten vehicular algunos de los temas más emblemáticos de su obra, a saber: el espejismo de la identidad o cómo se puede ser la misma persona en dos tiempos diferentes («El otro», " 25 de agosto, 1983»); la diferencia entre el tiempo objetivo y el tiempo subjetivo ("El milagro secreto», «El inmortal»); la confusión de planos entre el sueño y la realidad («Las ruinas circulares», el poema «Ajedrez»); el problema de la representación de la realidad a través del lenguaje («Tlön, Uqbar, Orbis Tertius»); el papel de la memoria y el olvido en la construcción del conocimiento («Funes, el memorioso»).

De este fértil contagio con la filosofía, es indudable que su obra sale reforzada, pues llega a alcanzar unas cuotas muy altas de virtuosismo narrativo y de profundidad al mismo tiempo, aspectos que no suelen coincidir en un mismo texto.

No es solo que la filosofía le inspire a Borges argumentos que les añaden interés y originalidad a sus ficciones literarias. Es también que sus ficciones literarias han conseguido renovar el interés por ciertas teorías filosóficas, tanto clásicas como actuales, que las hacen aún más atractivas para los lectores no especializados.

Por eso, no parece exagerado afirmar que Borges consiguiera algo así como la cuadratura del círculo, al demostrar que la metafísica no es tanto un camino para la búsqueda de la verdad como un estímulo eficaz para la producción literaria. 
